\title{
UM ESTUDO SOBRE O HABEAS CORPUS 124.306-RJ/STF NA PERSPECTIVA HERMENÊUTICA: TENSÃO ENTRE O CRIME DE ABORTO E OS DIREITOS FUNDAMENTAIS DA MULHER
}

\author{
Línikek Gabriel Lima da Silva* \\ Linara Oeiras Assunção ${ }^{* *}$
}

\section{Resumo:}

Trata-se de estudo de caso cujo escopo é investigar, em uma perspectiva hermenêutica, a questão: considerando a argumentação suscitada no Habeas Corpus (HC) $\mathrm{n}^{\circ}$ 124.306-RJ/STF, como interpretar a tensão entre a tutela do direito à vida no crime de aborto e os direitos fundamentais da mulher no contexto democrático brasileiro? A abordagem é qualitativa, com enfoque interpretativo, fundamentando-se em levantamento bibliográfico e na discussão dos argumentos atinentes ao HC. A questão é relevante, pois movimentou setores sociais, políticos e jurídicos da plural sociedade brasileira, lançando luzes sobre um tema complexo e que alimenta considerável dissenso.

Palavras-chave: habeas corpus $\mathrm{n}^{\mathrm{o}}$ 124.306-rj/stf. crime de aborto. direito à vida. direitos fundamentais da mulher.

\section{THE CASE OF THE HABEAS CORPUS PETITION N 124.306-RJ/STF IN THE HERMENEUTICS PERSPECTIVE: TENSION BETWEEN ABORTION CRIME AND WOMEN'S FUNDAMENTAL RIGHTS}

\begin{abstract}
:
This is case study whose scope is to investigate, from a hermeneutics perspective, the question: considering the arguments raised in Habeas Corpus petition $n^{\circ} 124.306-\mathrm{RJ} / \mathrm{STF}$, how to interpret the tension between the protection of the right to life in abortion crime and women's fundamental rights in the brazilian democratic context? The research is qualitative, with interpretative approach, based on bibliographic survey and discussion of arguments related to Habeas Corpus petition. The issue is relevant, because it moved social, political and legal sectors of the plural brazilian society, clarify on a complex subject that feeds considerable dissensus.
\end{abstract}

Keywords: habeas corpus petition $\mathrm{n}^{\circ}$ 124.306-rj/stf. abortion crime. rigth to life. women's fundamental rights.

\footnotetext{
* Coordenador de Planejamento, Orçamento e Modernização Administrativa da Prefeitura Municipal de MacapáAP. Advogado. Especialista em Direito Público pela Pontifícia Universidade Católica de Minas Gerais (PUC MINAS) (2019). Bacharel em Direito pelo Centro de Ensino Superior do Amapá (CEAP) (2015). Macapá-AP. Brasil.lih.lima28@gmail.com

** Professora Adjunta no Curso de Direito da Universidade Federal do Amapá (UNIFAP). Professora Colaboradora no Mestrado Profissional em Estudos de Fronteira da Universidade Federal do Amapá (UNIFAP). Doutora em Direito pela Universidade Federal de Minas Gerais (UFMG) (2017). Mestre em Direito Ambiental e Políticas Públicas pela Universidade Federal do Amapá (UNIFAP) (2009). Macapá-AP. Brasil. lioeiras@hotmail.com
} 


\section{INTRODUÇÃO}

Este estudo de caso tem por escopo investigar por meio da decisão exarada no acórdão do Habeas Corpus (HC) n 124.306 - RJ/STF, de relatoria do Ministro Marco Aurélio Mello, $1^{\text {a }}$ Turma do Supremo Tribunal Federal (STF), julgado em 29/11/2016, DJe: 24/04/2017, com base numa perspectiva hermenêutica, a tensão entre o crime de aborto e os direitos fundamentais da mulher sob a égide do Estado Democrático de Direito Brasileiro.

Tratou-se de pedido de liberdade junto ao STF de pacientes que estavam presos preventivamente em razão de suposto cometimento dos crimes elencados nos artigos 126, provocar aborto com consentimento da gestante, e 288, formação de quadrilha, ambos do Código Penal, dada denegação em habeas corpus anteriormente impetrado junto ao Superior Tribunal de Justiça (STJ).

No acórdão não fora conhecida a impetração, mas concedida ordem de ofício para afastar a prisão preventiva dos pacientes, estendendo-se aos corréus. Ocorre que a decisão tomou um rumo inesperado no instante em que o redator do acórdão, o Presidente da $1^{\mathrm{a}}$ Turma, Ministro Luís Roberto Barroso, em voto-vista, decidiu pela descriminalização constitucional do aborto até o terceiro mês de gestação.

Entendeu-se que a criminalização do aborto antes de concluído o primeiro trimestre da gestação, viola direitos fundamentais da mulher, quais sejam o direito à autonomia, direito à saúde física e psíquica, direitos sexuais e de reprodução e direito de igualdade, além de não observar com precisão o princípio da proporcionalidade e que, portanto, era preciso dar interpretação conforme à Constituição Federal de 1988 (CF/88) aos art. 124 e 126 do Código Penal.

A questão a ser tratada aqui, a partir deste HC, envolve a colisão de direitos fundamentais garantidos ao feto (vida) e à mulher. Tais direitos encontram-se preconizados na $\mathrm{CF} / 88$ e serviram, os próprios, para fundamentação da decisão, quais sejam o art. $1^{\text {o }}$, III, ao cuidar da dignidade da pessoa humana, como princípio fundamental republicano, art. $5^{\circ}$, caput, em se tratando da inviolabilidade do direito à vida, à liberdade (autonomia), à igualdade, bem como o inciso III do artigo, ao tratar da não submissão de pessoa alguma à tortura ou a tratamento desumano ou degradante. Suscitou-se, também, como fundamento supralegal, o Capítulo VII, §7.3 do Relatório da Conferência do Cairo, que tem o Brasil como signatário, emitido via Conferência Internacional da População e Desenvolvimento 
(Plataforma de Cairo), realizada em 1994, tratando os direitos sexuais e reprodutivos como direitos humanos fundamentais.

Ainda que tal decisão tenha mobilizado segmentos da sociedade e do Congresso Nacional, que a entendeu como atuação positiva (ativismo judicial) por parte do STF, não se vislumbra proposta de alteração do entendimento pela Corte Constitucional, registrando-se apenas que é assunto que há muito se discute no Parlamento, com projetos de lei ainda em análise, mas sem qualquer definição.

Desta forma, busca-se perquirir, considerando a argumentação jurídica suscitada no $\mathrm{HC} \mathrm{n}^{\mathrm{o}}$ 124.306-RJ/STF, como interpretar a tensão entre a tutela do direito à vida prevista no crime de aborto e os direitos fundamentais da mulher no contexto do Estado Democrático de Direito Brasileiro?

Constitui uma questão relevante a ser respondida, uma vez que se acredita que tal HC auxiliou na sistematização da temática do aborto, movimentando os setores sociais, políticos, jurídicos, lançando luzes sobre um tema tão complexo e com grande repercussão que ainda alimenta considerável dissenso na plural comunidade brasileira.

A investigação seguiu uma pesquisa qualitativa, com abordagem interpretativocompreensiva através de estudo de caso e fundamentou-se em levantamento bibliográfico e na discussão de argumentos atinentes ao $\mathrm{HC} \mathrm{n}^{\circ} 124.306$ - RJ/STF.

\section{O CAMINHAR DA JURISDIÇÃO CONSTITUCIONAL NA TEMÁTICA DO} ABORTO

Este estudo possui relação, dentre outros, com os tipos previstos nos artigos 124 e 126 do Código Penal e, desse modo, pesquisando a palavra "aborto" no campo de busca da jurisprudência do sítio eletrônico do Superior Tribunal de Justiça (STJ), foi possível encontrar 127 (cento e vinte e sete) acórdãos, 870 (oitocentas e setenta) decisões monocráticas e 10 (dez) informativos de jurisprudência relacionados ao signo. No que diz respeito ao Supremo Tribunal Federal (STF), utilizando a mesma metodologia para busca da jurisprudência, o resultado foi de 82 (oitenta e dois) acórdãos.

Registre-se que, muito embora haja um número expressivo de julgados, estes não necessariamente trazem em seu conteúdo a discussão sobre a temática em tela, tendo sido o número evidenciado para demonstrar a relevância de uma problemática presente no cotidiano 
brasileiro e que tão somente agora parece dar sinais de resolução, destacando-se para essa compreensão os mais paradigmáticos e/ou que sejam intrínsecos ao objeto do estudo.

Até o advento do nova concepção prolatada pelo STF, havia duas realidades que se colidiam e o Poder Judiciário, pelo Princípio da Inafastabilidade da Jurisdição, uma vez provocado, precisou dar resposta. Sob essa ótica e até sua consecução, exsurgiram entendimentos dicotômicos, materializados nos acórdãos de peças constitucionais.

Assim, a evolução da jurisprudência neste estudo se inicia com o Habeas Corpus $n^{\circ}$ 56.572 - SP/STJ, seguido do Habeas Corpus no 32.159 - RJ/STJ, Habeas Corpus no 84.025-6 - RJ/STF e pela Ação Direta de Inconstitucionalidade no 3.510 - DF/STF, Arguição de Descumprimento de Preceito Fundamental no 54 - DF/STF, até culminar no Habeas Corpus $n^{\circ}$ $124.306-\mathrm{RJ} / \mathrm{STF}$.

No que concerne ao STJ, a interpretação dos magistrados divergia entre si e para cada caso. Como forma de exemplificar tal ponto de vista e demonstrar o comportamento da jurisprudência, colaciona-se 02 (dois) casos em que se buscou a tutela da Corte Superior em situação de abortamento ou antecipação terapêutica do parto.

No julgamento do Habeas Corpus preventivo no 56.572 - SP/STJ, de relatoria do Ministro Arnaldo Esteves Lima, postulou-se a tutela do casal de pacientes que buscava autorização da Justiça para proceder à interrupção da gestação de feto que apresentava anomalia incompatível com a vida extra-uterina, vez que, requerida autorização junto ao Tribunal de Justiça de São Paulo, esta fora denegada.

Muito embora a ordem impetrada tenha restado prejudicada em razão da gestação ter atingido seu termo final, em suas considerações do voto, o Ministro Arnaldo Lima considerou na fundamentação o choque entre os direitos fundamentais em jogo, ponderando a questão do feto, cuja perspectiva de vida inexistia, e da gestante, que se encontrava em estado de abalo, tendo sua dignidade afetada por conta da decisão antes proferida. Avaliou o Ministro que tal situação:

[...] impõe reflexões com os olhos voltados para a Constituição Federal e para os princípios nela contidos, sob pena de transformar a norma criada para proteger bens jurídicos essenciais em instrumento de desamparo, de abandono, afastada dos objetivos fundamentais da República Federativa do Brasil, que é "construir uma sociedade livre, justa e solidária" (CF, art. $3^{\circ}$, inc. I), promovendo “... o bem de todos, sem preconceitos (...) e quaisquer outras formas de discriminação" (CF, art. $3^{\circ}$, inc. IV) (BRASIL, 2006). 
Além disso, trouxe no voto a ideia da relatividade do direito à vida ante a outros princípios também preconizados na Constituição Federal.

De outro modo, no julgamento do Habeas Corpus no 32.159 - RJ/STJ, cuja relatoria competiu à Ministra Laurita Vaz, buscou-se tutelar o direito à vida de nascituro contra decisão da Segunda Câmara Criminal do Tribunal de Justiça do Rio de Janeiro que autorizou abortamento de feto diagnosticado com anencefalia, sem que incorressem os pais e demais envolvidos no cometimento do crime de aborto.

$\mathrm{O}$ voto prolatado pela Ministra Laurita Vaz apreciou a matéria estritamente sob o enfoque jurídico, isto é, naquilo em que as leis vigentes aferem. Em sua concepção, a antecipação do parto ou aborto, nos moldes em que se propôs, não buscava respaldo nas exceções feitas pelo legislador asseveradas na lei penal (art. 128, I e II), e que portanto, a decisão do Tribunal de Justiça do Rio de Janeiro estaria atentando contra a vontade do Parlamento. Além disso, não houve por parte dela qualquer consideração acerca dos direitos da gestante. Pior que isso. Disse a ministra que "o máximo que podem fazer os defensores da conduta proposta nos autos originários é lamentar a omissão, mas nunca exigir do Magistrado, intérprete da Lei, que se lhe acrescente mais uma hipótese que [...] fora excluída de forma propositada pelo Legislador" (BRASIL, 2004a), ou seja, nada poderiam fazer a não ser dar prosseguimento na gestação, sob pena de perpetrarem o crime discutido.

Não por acaso e adentrando na seara da jurisprudência do Supremo Tribunal Federal, a parte interessada do HC anteriormente mencionado impetrou o Habeas Corpus $n^{\circ}$ 84.025-6 RJ/STF, de relatoria do Ministro Joaquim Barbosa, pleiteando preventivamente a tutela da Suprema Corte para que pudessem efetuar a antecipação do parto nos mesmos termos do pedido denegado pelo STJ.

A ação em questão restou prejudicada em razão de ter ocorrido o parto do bebê anencefálico, que veio a óbito minutos depois. O ministro Joaquim Barbosa fundamentou seu voto apontando a ponderação que deve ser feita em casos como o que se relata, onde a antecipação do parto, nesses termos, não configuraria fato típico, vez que a sobrevida do feto estava limitada pela anomalia diagnosticada e que, sim, a gestante teria o direito de decisão sobre prosseguir ou não com a interrupção. Fez, inclusive, alusão à questão do aborto sentimental, em que prevalece a dignidade sexual da mulher em detrimento da vida de um feto que poderia potencialmente vir a se tornar uma pessoa. Disse o ministro que: 
Seria um contra-senso chancelar a liberdade e a autonomia privada da mulher no caso do aborto sentimental, permitido nos casos de gravidez resultante de estupro, em que o bem jurídico tutelado é a liberdade sexual da mulher, e vedar o direito a essa liberdade nos casos de malformação fetal gravíssima, como a anencefalia, em que não existe um real conflito entre os bens jurídicos detentores de idêntico grau de proteção jurídica. Há, na verdade, a legítima pretensão da mulher em ver respeitada sua vontade de dar prosseguimento à gestação ou de interrompê-la, cabendo ao direito permitir essa escolha, respeitando o princípio de liberdade, da intimidade e da autonomia privada da mulher (BRASIL, 2004b).

Fica claro, portanto, na perspectiva do magistrado que, muito embora estejam tais direitos salvaguardados pela Lei Maior, a depender da circunstância e da análise entre eles, um prevalecerá em detrimento do outro.

Ademais, sob a jurisdição da Corte Suprema pairaram outras demandas de grande repercussão e que envolvem a problemática existente entre a colisão de direitos fundamentais, quais sejam a Ação Direta de Inconstitucionalidade n 3.510 - DF/STF, que cuidou de julgar a constitucionalidade de dispositivo da Lei $n^{0} 11.105$ de 24 de março de 2005, a Lei de Biossegurança, e a Arguição de Descumprimento de Preceito Fundamental no 54 - DF/STJ, que tratou de julgar inconstitucional a interpretação de que aborto de feto anencefálico caracterizaria os crimes previstos nos arts. 124 e 126 do Código Penal.

No tocante à $\operatorname{ADIN~} n^{\circ} 3.510$, requereu-se a declaração de inconstitucionalidade do artigo $5^{\circ}$ da Lei 11.105/05, qual seja:

Art. $5^{\mathrm{o}}$ É permitida, para fins de pesquisa e terapia, a utilização de células-tronco embrionárias obtidas de embriões humanos produzidos por fertilização in vitro e não utilizados no respectivo procedimento, atendidas as seguintes condições:

I - sejam embriões inviáveis; ou

II - sejam embriões congelados há 3 (três) anos ou mais, na data da publicação desta Lei, ou que, já congelados na data da publicação desta Lei, depois de completarem 3 (três) anos, contados a partir da data de congelamento.

$\S 1^{\circ}$ Em qualquer caso, é necessário o consentimento dos genitores.

$\S 2^{\underline{o}}$ Instituições de pesquisa e serviços de saúde que realizem pesquisa ou terapia com células-tronco embrionárias humanas deverão submeter seus projetos à apreciação e aprovação dos respectivos comitês de ética em pesquisa.

$\S 3^{\mathrm{o}}$ É vedada a comercialização do material biológico a que se refere este artigo e sua prática implica o crime tipificado no art. 15 da Lei $n^{\circ} 9.434$, de 4 de fevereiro de 1997.

Dentre as teses levantadas, a autorização contida no referido dispositivo estaria atentando contra o direito à vida, não somente pela destinação que se propôs dar aos embriões "descartáveis", mas porque ventilou-se que a utilização destes, conforme proposição, configuraria aborto. Tal tese foi rechaçada no julgamento, pois segundo a compreensão construída, para configuração de aborto, o embrião deveria estar fecundado no útero feminino 
em fase de gestação e, após isso, sua retirada, fora das circunstâncias permitidas em lei, é que configuraria crime, o que não ocorria pois a fecundação aconteceria "in vitro".

Não obstante, ainda que não se cuide especificamente de caso de aborto, trazer esse julgado se faz importante em razão da preponderância contida em alguns dos argumentos suscitados nos votos, temas afetos ao estudo, como as teorias sobre a vida, no sentido de quando ela se inicia, se com a concepção (teoria concepcionista) ou com o nascimento com vida propriamente dito (teoria natalista), matéria ainda controvertida no ordenamento jurídico brasileiro, e, nesse aspecto, se o embrião já teria ou não direitos garantidos, além da invocação doutros direitos constitucionais como o princípio da paternidade responsável que, ao lado da liberdade de escolha, autonomia privada e respaldados na dignidade da pessoa humana, garante às pessoas, e aqui reflita-se sobre a mulher, o direito de escolher quando e como desenvolver uma família, além de não estarem, por via de consequência, obrigados pelo Estado a ter filhos dos demais embriões fecundados.

A ADI n 3.150 - DF/STF foi julgada improcedente por maioria dos votos, entendidos os ministros que os dispositivos da Lei de Biossegurança não atentavam contra a dignidade da pessoa humana e à vida.

Em se tratando de Arguição de Descumprimento de Preceito Fundamental no 54 DF/STF, a Confederação Nacional dos Trabalhadores na Saúde (CNTS) postulou pedido para que fosse declarada inconstitucional a interpretação de que a interrupção de gestação de feto anencefálico seria conduta tipificada nos arts. 124 e 126 do Código Penal, vez que, de modo adverso, atentaria aos preceitos fundamentais preconizados nos arts. $1^{\circ}$, IV (princípio da dignidade da pessoa humana), $5^{\circ}$, II (princípio da legalidade e princípio da autonomia da vontade humana), 6º caput e 196 (direito à saúde).

O julgamento da ADPF $n^{\circ} 54$ culminou na discussão massificada no tocante à condição do feto e à condição da mulher que, mais uma vez, colidiam-se em direitos salvaguardados pela Constituição e cuja análise de mérito resultaria em efeito erga omnes, vez que se chegaria a um denominador comum no que se refere a "(a)tipicidade da antecipação terapêutica do parto", trazendo à baila todo o arcabouço jurídico fundamentador das ações antes elencadas, tais quais, a exemplo, destacaram-se a laicidade do estado, teorias sobre a vida e o fim desta, quando identificada a morte cerebral, tanto sob o ângulo jurídico como sob o biológico e como considerá-las, o entendimento dado pela doutrina acerca do 
aborto, além do argumento de que poderia ser considerada tortura impor à mulher a obrigação de manter a gestação nessas condições, trazendo riscos também à sua saúde.

Desta feita, na compreensão majoritária, o feto diagnosticado com anencefalia não possui qualquer perspectiva de vida extra-uterina e que, assim sendo, a interrupção da gestação nesses casos não caracteriza fato típico, não atentando contra o bem jurídico tutelado pela legislação penal, isto é, não haveria uma vida potencial a ser protegida pelo Direito, requisito considerado como essencial para a materialização do crime de aborto.

Divergiu com afinco o ministro Cézar Peluso que posicionou-se no sentido de que o feto, ainda que possuidor de anencefalia, vivo se encontrava no útero de sua mãe e que, portanto, a ele estaria garantida a tutela pelo ordenamento constitucional e que, sim, a interrupção da gestação configuraria crime de aborto, questão esta não excepcionada pelo legislador, e que tal prática estaria próxima de práticas eugênicas, vedadas pelo direito.

Não obstante, a ADPF n ${ }^{\circ} 54$, por maioria dos votos, foi julgada procedente.

Em todos os casos apresentados fica evidenciada a tríade conflituosa entre os direitos do feto, direitos da mulher e a configuração ou não de crime de aborto. Tal questão se acentuou ainda mais com o novo entendimento do Supremo Tribunal Federal emanado através da decisão proferida no Habeas Corpus nº 124.306 - RJ/STF.

\section{DA COLISÃO DE DIREITOS FUNDAMENTAIS: TENSÃO ENTRE A TUTELA DO DIREITO À VIDA PREVISTA NO CRIME DE ABORTO E OS DIREITOS FUNDAMENTAIS DA MULHER}

Tratar-se-á daquilo que a doutrina disserta acerca da colisão de direitos fundamentais, com base em Alexy (2008), Steinmetz (2000) e Avanci (2010), visões sobre aborto/vida do feto versus condição da mulher, em Martins (1999) e Sarmento (2006), e sobre a técnica da ponderação como forma de resolver o fenômeno de colisão de direitos, para Barcelos (2018), Sarlet (2017), Alexy (2008), Mendes (2000) e Streck (2013; 2018).

Alexy leciona que há colisão de direitos "quando duas normas, se isoladamente aplicadas, levariam a resultados inconciliáveis entre si, ou seja, a dois juízos concretos de dever-ser jurídico contraditórios" (ALEXY, 2008, p. 92).

Em seu postulado, para que se entenda melhor o conceito de colisão, Alexy (2008) explica que as referidas normas são havidas como regras, que estipulam o que se pode ou o 
que não se pode fazer, e princípios, tidos por mandamentos de otimização, onde o conflito entre regras pode ser resolvido com a inclusão de uma cláusula de exceção, desencadeando a subsunção de uma regra sobre a outra, sem perda de sua normatividade ou, não sendo possível a referida verificação, uma das regras conflitantes deverá ser declarada inválida, sendo extirpada do ordenamento jurídico, dando termo ao conflito. No caso dos princípios, a questão é tratada de maneira diferente no sentido de que, havendo colisão de princípios, um deverá ceder em face do outro, sem, contudo, incidir na necessidade de inclusão de cláusula excepcional, declaração de invalidade ou perda do núcleo essencial ${ }^{1}$.

As normas de direito fundamental em análise, conforme art. $5^{\circ}, \S 1^{\circ}$ da $\mathrm{CF}$, possuem aplicação imediata, isto é, havidas como princípios, e sob este ponto se constrói o estudo, abstratamente, seus efeitos têm eficácia imediata, e, desse modo, não se percebe o fenômeno da colisão, diferentemente do que demonstra Alexy (2008) em seu conceito, se aplicadas ao mesmo tempo em um caso concreto.

$\mathrm{Na}$ questão abordada pela pesquisa, e valendo-se dos ensinamentos supramencionados, garantir isoladamente o direito fundamental do feto (art. $1^{\circ}$, III e art. $5^{\circ}$, caput, $\mathrm{CF}$ c/c arts. 124 e 126 do CP) e garantir isoladamente os direitos fundamentais da mulher (art. $1^{\circ}$, III c/c art. 5 $5^{\circ}$, caput, III e Capítulo VII, §7.3 do Relatório da Conferência do Cairo), em torno da interrupção voluntária da gestação, denota clara colisão de direitos, ou seja, não há concordância na aplicação efetiva de ambos os interesses em um mesmo caso concreto.

Avanci possui entendimento diverso ao expor que

[...] no caso concreto e individual, haverá sim o pleno esvaziamento de um Direito
Fundamental em detrimento do outro Direito Fundamental. Em outras palavras, em
uma situação concreta e individual julgada, um Direito Fundamental é plenamente
reconhecido àquela determinada situação e outro Direito Fundamental não é
reconhecido àquela determinada situação. Não seria isso um exame de subsunção?
Apesar dos esforços em se afirmar que o "núcleo essencial" do Direito Fundamental
"perdedor" estaria mantido intacto, naquela determinada situação julgada, ao que
parece, houve um esvaziamento total do referido Direito. A colisão, em resumo, será
sempre de interesses e nunca de direitos. (AVANCI, 2010, p. 198)

Desta forma, não se estaria diante de uma situação de conflito de direitos fundamentais, mas sim de colisão de interesses em que, feita a análise do caso concreto, o interesse de uma parte vai subsumir ao da outra parte, em outras palavras, para fins do estudo,

\footnotetext{
${ }^{1}$ Para aprofundamento do tema, cf. ALEXY, Robert. Teoria dos Direitos Fundamentais. 5a ed. Tradução de Virgílio Afonso da Silva. São Paulo: Malheiros, 2008.
} 
não haveria colisão de direitos fundamentais entre o feto e a mulher, mas tão somente colisão de interesses de ambos a serem garantidos.

Antes de discorrer sobre o que a doutrina leciona acerca da colisão de direitos fundamentais em espécie, isto é, em relação à visão acerca do aborto e da condição da mulher, cumpre frisar, preliminarmente, que, conforme entendimento do STF os direitos e garantias individuais não têm caráter absoluto. Não há, no sistema constitucional brasileiro, direitos ou garantias que se revistam de caráter absoluto (BRASIL, 2000).

Tal disposição não se confunde com o fato de os direitos fundamentais, tidos aqui enquanto princípios, estarem dispostos no texto constitucional como de aplicação imediata, isto é, pelo fato de se caracterizarem como mandamentos de otimização, conforme Alexy (2008, p.104), em que se deva realizar algo "na maior medida possível dentro das possibilidades jurídicas e fáticas existentes", não significa que eles estejam revestidos de caráter absoluto.

Nesse sentido, Barcellos explica que

[...] a interpretação dos direitos fundamentais previstos na Constituição exige a consideração de outras diretrizes hermenêuticas, que decorrem de forma direta da circunstância de se tratarem de normas constitucionais. Em primeiro lugar, a superioridade hierárquica reconhecida a tais direitos: sua interpretação e aplicação envolverá não apenas a incidência sobre circunstâncias de fato, mas tais normas servirão igualmente como parâmetro de controle para outras normas e atos no âmbito do Estado. Em segundo lugar, e considerando a premissa de que todas as normas constitucionais são dotadas de igual superioridade, não havendo hierarquia entre elas, será preciso considerar o chamado princípio da unidade da Constituição: não se poderá interpretar um direito de modo a esvaziar outro, sendo necessário garantir que a vigência de todos seja respeitada, ainda que por meio de compressões recíprocas. (BARCELLOS, 2018, p. 218-219).

As normas constitucionais, em especial os direitos fundamentais, portanto, não possuem hierarquia entre si, devendo sua essência manter-se resguardada, ainda que em situações de colisão, como é o caso.

Para Mendes (2000, p. 283) "uma valoração hierárquica diferenciada de direitos individuais somente é admissível em casos especialíssimos".

Não é equívoco entender que o direito à vida pressupõe, ao menos em tese, o exercício dos demais direitos, contudo, como já verificado, a jurisprudência e a legislação não fazem ressalvas acerca da precedência de um direito fundamental em face do outro.

Diversamente disso, a doutrina mostra-se ambivalente acerca da temática da interrupção voluntária da gestação fora das hipóteses previstas no art. 128 do Código Penal 
(aborto necessário e aborto sentimental), onde a dignidade humana e direito fundamental à vida do feto prevaleceriam sobre a dignidade humana e os direitos fundamentais da mulher e vice-versa, tecendo comentários colidentes sobre a vida com consequente proteção desse direito em relação ao feto, bem como o status da mulher nesse contexto.

Desse modo, na compreensão de Martins (1999), discorrendo sobre o direito fundamental à vida e sobre o aborto, afirma que aquele direito, sim, teria preferência em face dos demais direitos fundamentais e que, dessa forma, vincularia o Estado a garantir sua proteção, especialmente em relação ao direito à vida do "insuficiente", entendido aqui o feto.

Segue afirmando que:

\footnotetext{
Os argumentos [..] de que o aborto não é atentado ao direito à vida, mas o exercício de um direito ao corpo que a mulher possui, não prevalecem, visto que se a própria natureza feminina a faz hospedeira do direito à vida de outrem. No momento em que a concepção se dá, já não é mais titular solitária de seu corpo, que pertence também a seu filho. (MARTINS, 1999, p. 135)
}

Qualquer direito fundamental garantido à mulher (autonomia, direito à saúde física e psíquica, direitos sexuais e reprodutivos e igualdade) nesta perspectiva não prevaleceria sobre o direito à vida do feto, desde sua concepção, pois, conforme raciocínio externado, a mulher ao engravidar deixa de ser titular de seu próprio corpo, vez que torna-se "hospedeira" de uma vida que se está a gerar.

O que se depreende da argumentação levantada é que a mulher, muito mais do que pessoa de direitos, está sendo concebida como "mera ferramenta da natureza" para fins de procriação onde, uma vez gestante, perde a titularidade plena do próprio corpo em razão de estar gerando uma vida que deve ser protegida sob qualquer circunstância, reforçando a ideia de que, não importando a situação em que se encontre, torna-se ela coagida por isso a ser uma verdadeira "incubadora" do feto, e deste apenas estão garantidos os direitos.

Em suma, Martins (1999) entende que abortar é uma violação do mais fundamental dos direitos, a vida, e que sua prática nada mais é do que ação diletante por parte da mulher que "se vê violada do direito de coito livre", não havendo possibilidade de seus direitos fundamentais prevalecerem em detrimento do direito à vida do feto.

Em contraponto, Sarmento (2006), ao discutir a questão da legalização do aborto à luz da Constituição Federal, considera uma relativização do direito fundamental à vida do feto em face dos direitos fundamentais da mulher, uma vez verificada a colisão entre esses direitos sob a perspectiva da interrupção voluntária da gestação, levando em consideração que o tema 
deve guardar relevo com o Estado Democrático e pluralista que é o Brasil, sem olvidar a proteção jurídica devida ao feto nas fases de desenvolvimento intra-uterino.

Não se trata de desconsiderar a vida que se desenvolve na mulher, vez que o ordenamento jurídico não deixa de salvaguardá-la como bem ou valor digno de ser tutelado, todavia se contingencia enquanto bem constitucionalmente protegido sob a forma de direito fundamental das pessoas, ou seja, possui proteção diferenciada, com menos força do que a proteção garantida à pessoa propriamente dita, já detentora de personalidade jurídica, razão pela qual se depara em colisão de direitos da mulher em relação à interrupção voluntária da gestação.

Há, por outro lado, quem sustente que, sendo o Brasil signatário do Pacto de São José da Costa Rica, por incidência do seu art. $4.1^{2}$, o ordenamento jurídico brasileiro deva dar plena proteção à vida desde a concepção. A esse respeito, Sarmento preleciona que:

Com efeito, a tese que ora se sustenta também parte da premissa de que a proteção da vida se inicia no momento da concepção. Apenas afirma que a tutela da vida anterior ao parto tem de ser menos intensa do que a proporcionada após o nascimento, sujeitando-se, com isso, a ponderações de interesses envolvendo outros bens constitucionalmente protegidos, notadamente os direitos fundamentais da gestante. Aliás, o emprego da expressão "em geral", no texto do artigo em discussão, revela com nitidez que as partes celebrantes do tratado não quiseram conferir à vida intra-uterina uma proteção absoluta. (SARMENTO, 2006, p. 149)

Não se desconsidera a vida concepta, mas a trata de modo relativo frente a outros direitos constitucionalmente previstos em caso de colisão, ressalvando-se, ainda e de acordo com o autor, não ser entendida como absoluta nem mesmo pelo tratado internacional em comento.

Sarmento complementa que

[...] esse entendimento se reforça diante da interpretação sistemática da Convenção Interamericana dos Direitos Humanos. É que a Convenção consagra em seu bojo uma série de outros direitos, titularizados também pelas gestantes, que podem entrar em colisão com a proteção à vida embrionária: é o caso do direito ao respeito da integridade física, psíquica e moral (art. $\left.5^{\circ}, 1\right)$, do direito à liberdade e segurança pessoais $\left(\operatorname{art.} 7^{\circ}, 1\right)$, do direito de proteção à vida privada (art. 11,2$)$, dentre outros. Assim, a atribuição de um peso absoluto à proteção da vida do nascituro implicaria, necessariamente, a lesão a esses direitos, razão pela qual torna-se essencial a sua relativização (SARMENTO, 2006, p. 149).

\footnotetext{
${ }^{2}$ Art. 4.1 - toda a pessoa tem direito a que se respeito sua vida. Esse direito deve ser protegido pela lei, em geral, desde o momento da concepção. Ninguém pode ser privado da vida arbitrariamente.
} 
Fica claro, portanto, que, muito embora esteja a vida intra-uterina protegida pelo ordenamento jurídico brasileiro, no contexto do aborto tal proteção se encontra relativizada quando confrontada aos direitos fundamentais também garantidos à mulher que objetiva interromper a gestação, ressaltando-se que tais direitos não só constam previstos pelo texto da Constituição, mas também preconizados em tratados internacionais afetos à matéria, para cuja força normativa está em mesmo nível ao direito fundamental à vida, dada a inexistência de hierarquia entre eles.

No intuito de resolver demandas em que figura a colisão de direitos fundamentais, a jurisdição brasileira tem se valido, a exemplo do Ministro Luís Roberto Barroso ao emitir seu voto no HC 124.306 - RJ/STF, da metodologia utilizada pelo Tribunal Constitucional Federal da Alemanha e discorrida por Alexy (2008), a técnica da ponderação subsidiada pela máxima da proporcionalidade e suas submáximas, da adequação, da necessidade e da proporcionalidade em sentido estrito.

Alexy (2008) entende que o trato dado à colisão entre princípios se perfaz quando, em um caso concreto, a realização de um princípio obsta a concretização do outro. Assim, sopesados sob determinadas condições que constituirão o suporte fático para precedência e, por conseguinte, originando uma consequência jurídica da razão de sopesar, um deles terá precedência em relação ao outro. Essa proposição consubstanciou em seu estudo o que ele denominou de "lei de colisão".

Nesse interim, é mister rememorar que o direito fundamental do feto e os direitos fundamentais da mulher constam dispostos abstratamente no texto constitucional e que, como já esclarecido, além de imediatamente aplicados, não possuem hierarquia entre si. No contexto da interrupção da gestação fora dos casos autorizados pela lei, esses direitos, havidos como princípios e na perspectiva delineada por Alexy (2008) colidem-se no tocante aos interesses das partes (feto e mulher). Daí se questiona como então dar solução a essa colisão?

A concordância prática mediante compressões recíprocas reflete exatamente a ideia de ponderação que deve o juiz promover no caso concreto diante da colisão de direitos fundamentais, buscando fundamento na proporcionalidade, entendida como princípio para alguns e máxima (técnica) para outros.

$\mathrm{Na}$ visão de Sarlet a proporcionalidade "desponta como instrumento metódico de controle dos atos - tanto comissivos quanto omissivos - dos poderes públicos, sem prejuízo de sua eventual aplicação a atos de sujeitos privados" (SARLET, 2017, p. 410). 
Neste sentido, a proporcionalidade atuaria como legítima proibição de excesso e proibição de proteção do insuficiente dos atos dos poderes públicos, desde que atendidos os requisitos necessários à sua formulação através das suas submáximas que são a adequação, necessidade e proporcionalidade em sentido estrito.

Essa fora a técnica utilizada na construção do voto exarado no $\mathrm{HC} \mathrm{n}^{\circ} 124.306$ $\mathrm{RJ} / \mathrm{STF}$, objeto da pesquisa.

Não obstante, o instituto da ponderação possui críticos na doutrina, que asseveram ser esse mecanismo de solução de conflito entre direitos fundamentais mera discricionariedade por parte do juiz.

Streck (2018) refuta a proporcionalidade no âmbito de ponderação de direitos afirmando que a utilização dessa metodologia pela jurisdição brasileira tem se dado de maneira desarrazoada, sem levar de fato em conta os critérios de sopesamento no enunciado trazido por Alexy, consistindo, em verdade, em subjetivismo.

Assim, segundo Streck:

O que importa referir [...] é que a ponderação é uma regra e não um princípio. Todavia, o que é mais relevante ainda diz respeito ao modo equivocado de aplicação no Brasil, onde a ponderação de princípios é feita diretamente, colocando um "princípio" em cada "prato da balança" e disso extraindo o resultado...! Como consequência, em estando o intérprete diante de um "caso de colisão" de princípios, simplesmente sopesa um em relação ao outro e, fiat lux, está feita a "ponderação". O resultado? $\mathrm{Na}$ verdade, o resultado dependerá de um ato de vontade do intérprete. (STRECK, 2018, p. 293).

Ao criticar a proporcionalidade no âmbito de colisão de direitos, o autor verifica que o modo como as decisões envolvendo o fato se constrói consta emoldurado por discricionariedade do juiz frente a um caso de difícil solução quando, se valendo da ponderação, prolata uma decisão solipsista ${ }^{3}$.

Streck contribui, ainda, que

[...] é preciso deixar claro que existe uma diferença entre Decisão e Escolha. Quero dizer que a decisão - no caso, a decisão jurídica - não pode ser entendida como um ato em que o juiz, diante de várias possibilidades possíveis para a solução de um caso concreto, escolhe aquela que lhe parece mais adequada. Com efeito, decidir não é sinônimo de escolher. Antes disso, há um contexto originário que impõe uma diferença quando nos colocamos diante destes dois fenômenos. A escolha, ou a eleição de algo, é um ato de opção que se desenvolve sempre que estamos diante de

\footnotetext{
${ }^{3}$ Streck (2013) usa o termo "solipsismo judicial” para caracterizar a decisão exarada conforme a consciência do julgador. Decisão solipsista, portanto, seria decisão conforme a convicção subjetiva do magistrado.
} 
duas ou mais possibilidades, sem que isso comprometa algo maior do que o simples ato presentificado em uma dada circunstância. (STRECK, 2013, p. 45)

Ponderar, valendo-se da proporcionalidade, estaria no âmbito da escolha, diferentemente do que se entenderia por decisão, que materializa a imparcialidade, contrariamente ao que se dispõe, quando, ponderando, abre-se margem para subjetivismo.

\section{CONCLUSÃO}

Como conclusão, apresenta-se um posicionamento crítico acerca do acórdão do HC $n^{\circ} 124.306$ - RJ/STF e algumas consequências para o ordenamento jurídico brasileiro.

Para interpretar a tensão e, assim, responder ao problema proposto é preciso partir da perspectiva de que o tema "aborto" conduz à configuração de colisão de direitos fundamentais, quais sejam o direito à vida do feto contraposto à autonomia (liberdade), integridade física e psíquica, direitos sexuais e reprodutivos e igualdade de gênero no que concerne à mulher. Em havendo a colisão, entendemos que seja mister fazer uso da interpretação dos direitos fundamentais, à luz da Constituição Federal e do paradigma do Estado Democrático de Direito, através da ponderação das normas colidentes, levando-se em conta a máxima da proporcionalidade em seu caráter trifásico que deve orientar esse sopesamento, buscando, sobretudo, harmonizar os arts. 124 e 126 do Código Penal, frise-se, datado de 1940, à essência normativa da CF/88.

De pronto, é mister destacar diferenças peculiares entre o acórdão do Habeas Corpus $n^{\circ} 124.306$ - RJ/STF em relação aos acórdãos dos Habeas Corpus no 56.572 - SP/STJ, do Habeas Corpus no 32.159 - RJ/STJ, Habeas Corpus no 84.025-6 - RJ/STF, Ação Direta de Inconstitucionalidade $\mathrm{n}^{\circ} 3.510$ - DF/STF e Arguição de Descumprimento de Preceito Fundamental no $54-$ DF/STF.

No que tange às ações da jurisprudência revisada, não se despreza que houve suscitação de direitos fundamentais na fundamentação dos votos, que, em tese, houve conflito aparente desses direitos e que não houve divergência de entendimentos. Todavia, não foi assim, em plenitude, e não foi esse o mérito discutido, uma vez que tais ações (Habeas Corpus $n^{\circ} 56.572$ - SP/STJ, do Habeas Corpus no 32.159 - RJ/STJ, Habeas Corpus no 84.025-6 RJ/STF, Ação Direta de Inconstitucionalidade $\mathrm{n}^{\mathrm{o}} 3.510$ - DF/STF e Arguição de Descumprimento de Preceito Fundamental no 54 - DF/STF) travaram discussão envolvendo 
especificamente a vida sem potencialidade de sobrevivência, de existência (feto anencefálico e embriões fertilizados in vitro), o que foi suficiente para entender como fato atípico tanto a interrupção da gestação pós diagnóstico de anencefalia, quanto o descarte de embriões que não foram aproveitados para implante intra-uterino e que estivessem congelados há mais de três anos, ressalvada a autorização dos donos destes embriões.

Objetivamente, anui-se com o que bem acentuou o Ministro Marco Aurélio, relator da ADPF n ${ }^{\circ} 54$, em seu voto, ao afirmar que:

\begin{abstract}
Aborto é crime contra a vida. Tutela-se a vida em potencial. No caso do anencéfalo, repito, não existe vida possível. Na expressão do Ministro Joaquim Barbosa, constante do voto que chegou a elaborar no Habeas Corpus $\mathrm{n}^{\circ} 84.025 / \mathrm{RJ}$, o feto anencéfalo, mesmo que biologicamente vivo, porque feito de células e tecidos vivos, é juridicamente morto, não gozando de proteção jurídica e, acrescento, principalmente de proteção jurídico-penal. Nesse contexto, a interrupção da gestação de feto anencefálico não configura crime contra a vida - revela-se conduta atípica (BRASIL, 2013).
\end{abstract}

Essa lógica vale também para a tese refutada na ADI no 3.510 - DF/STF, de que o descarte dos embriões fertilizados ou utilização para pesquisa configuraria aborto, concebendo-se como "acerto" da jurisprudência.

Portanto, o tema aborto, em si, é afeto a todas as decisões, não obstante o raciocínio evidencia-se quando, donde não haja potencialidade de vida, não há que se falar em colisão de direitos e consequente necessidade de proceder à ponderação entre eles. A tensão entre o crime de aborto e os direitos fundamentais da mulher, neste aspecto é somente aparente. Subscreve-se essa posição.

No que diz respeito a "erros", evoque-se aqui o posicionamento contido no $\mathrm{HC} \mathrm{n}^{\circ}$ 32.159 - RJ/STJ, de relatoria da Ministra Laurita Vaz, discursado na Revisão da Jurisprudência.

Recordando, dentre as justificativas que conduziram a reforma da decisão do Tribunal de Justiça do Rio de Janeiro, constou a ideia de que a prática de interrupção de gestação de feto anencefálico não possuía respaldo legal conforme vontade expressa do legislador nas exceções do art. 128 e que, para tanto, não restava nada a se fazer além de lamentar a omissão legislativa e prosseguir com a gestação.

Pelo teor da decisão, houve uma valoração absoluta da vida sobreposta aos direitos da mãe, que sequer foram considerados no julgamento, direitos estes para quem buscava tutela com vistas a minimizar sua dor, direitos fundamentais invocados ad nauseam, também 
salvaguardados pelo ordenamento jurídico, tal qual a vida e na Constituição. O “erro”, por assim dizer, está para a não consideração dos direitos preconizados da mulher como parâmetro para interpretação da norma e resolução do caso concreto.

Já ao que toca ao acórdão do $\mathrm{HC} \mathrm{n}^{\circ} 124.306$ - RJ/STF, este traz consigo três questões principais interligadas: a opção pela ponderação construída com base no evento da colisão de direitos fundamentais garantidos ao feto e à mulher, a consequente descriminalização do aborto voluntário e assistido previstos nos arts. 124 e 126 do CP até o terceiro mês através dessa técnica e a consubstanciação desse resultado através de decisão do Supremo Tribunal Federal como guardião da Constituição. Aqui, cuida-se de direito à vida em potencial efetivamente colidente com outros direitos fundamentais, o que exige uma leitura de maior dimensão da legislação vigente para ponderação.

O Decreto Lei $n^{\circ}$ 2.848, Código Penal, é lei ordinária editada em 07 de novembro de 1940, concebido sob a vigência da Carta Magna de 1937 - "a Polaca”, dentro do paradigma constitucional do Estado Social, lei fundamental do Estado Novo que se instituiu no Brasil no período ditatorial do então presidente Getúlio Vargas. Sob esse prisma, devemos considerar o contexto histórico e social no qual o Código Penal foi editado, contexto este de uma sociedade de patriarcado, arraigada, mesmo com laicidade estatal prevista, tal qual ainda o é até hoje, em preceitos religiosos, machista, onde a participação da mulher era adstrita.

Está longe de equívoco suscitar que, ao tipificar o crime de aborto nos arts. $124 \mathrm{e}$ 126, o legislador ordinário levou em consideração tão somente a vida da gestante, em caso de restar prejudicada em função da gestação, e a honra da mulher vítima de estupro, mas acima disso, a honra da família - entenda-se do patriarca - violada por tal prática com a possibilidade de vir a nascer um filho bastardo. A tutela da vida, em si, não era uma prioridade nesse período. Prova disso é que a parte da Constituição de 1937 que cuidava dos direitos e garantias individuais ${ }^{4}$ não previa a vida como um desses direitos, mas tão somente a liberdade, segurança individual e a propriedade. Já a CF/88, de outro modo, inaugura o paradigma do Estado Democrático de Direito, trazendo consigo, dentre outros, um elenco de direitos fundamentais, a exemplo da vida, da liberdade e da igualdade, com mesmo peso, como orientadores da ordem social e das ações dos poderes estatais, e a ideia de uma sociedade plural, justa e igualitária, incluindo, ao menos em tese, a mulher nesse cenário de forma plena.

\footnotetext{
${ }^{4}$ Art 122 - A Constituição assegura aos brasileiros e estrangeiros residentes no País o direito à liberdade, à segurança individual e à propriedade, nos termos seguintes [...];
} 
O que se quer expor com isso é o fato de, muito embora ter sido recepcionado pela Constituição de 1988, o Código Penal, em especial os arts. 124 e 126 objeto da crítica, guarda, de modo geral, os valores e a vontade do legislador da época em que foram editados, um outro contexto histórico, com valores diferentes, tendo a mulher como coadjuvante, de modo que inexoravelmente exige-se interpretação dos referidos dispositivos sancionatórios com base no novo contexto fundamental do ordenamento jurídico pátrio através da jurisdição do STF que é o órgão legitimado para fazer valer a Constituição Federal e sua supremacia, afinal, como aponta Sarlet (2017, p. 393), "é a lei que se move no âmbito dos direitos fundamentais e não o oposto".

No caso, juiz sopesou esses direitos fundamentais com o intuito de verificar a preponderância entre eles, orientado pela máxima da proporcionalidade, levando em consideração as circunstâncias que envolvem o caso concreto para que se justificassem os objetivos que se almeja alcançar, que, para além da descriminalização relativa do aborto, garantiria à mulher o exercício desses direitos previstos, mas sem efetivo exercício, além de tentar ao menos reduzir o índice de mortalidade tanto do feto, quanto da mulher que, vendo-se sancionada pela lei, acaba por acessar meios nocivos para efetivar tal prática.

Conforme exposto, Alexy (2008) e Steinsmetz (2000), para o que se busca defender e averiguando a decisão, acertam ao explanar sobre a possibilidade de colisão de direitos fundamentais em um caso concreto e que sua ocorrência requer ponderação, diferentemente do que defende Avanci (2010) sobre o "conflito de interesses", uma vez que se compreende que tal proposição é frágil em razão de que os direitos, genericamente falando, tutelam ou respaldam interesses, portanto, se não há direito, não há interesse a ser tutelado ou respaldado.

De igual modo, considerando ser o entendimento do próprio Supremo tribunal Federal, não há hierarquia entre as normas constitucionais e, desta forma, não há que se falar em hierarquia entre os direitos fundamentais, além destes não possuírem caráter absoluto, conforme a orientação de Mendes (2000).

Partindo, então, do pressuposto de que não há hierarquia entre as normas constitucionais e, por consequência, entre os direitos fundamentais, e que estes não são absolutos, equivoca-se Martins (1999) ao externar que o direito à vida do feto sobrepõe-se sobre ao direitos garantidos à mulher, quando em período gestacional, restando-lhe a obrigação de levar até o fim a gestação, vez que ela não teria, dentre outros, plena autonomia de seu corpo. Diversamente, reflexionando a fundamentação legal suscitada, Sarmento acerta 
ao razoar que o direito à vida deve ser considerado como relevante, mas não absoluto, dada sua notória relatividade, como já mencionado e verificado, em face doutros direitos fundamentais, neste caso os da mulher, também preconizados na legislação constitucional e supralegal, o que dá ensejo à necessidade de ponderação no contexto da interrupção voluntária da gestação.

Em relação ao que disserta Streck (2018), coaduna-se ao que este afirma sobre a técnica da ponderação através da proporcionalidade que pode figurar como discricionariedade do juiz, todavia acredita-se que isso se relativiza quando não cumpridas as três fases da máxima da proporcionalidade, com a devida e reforçada fundamentação jurídica, o que, na nossa opinião, aconteceu perfeitamente na fundamentação do HC 124.306 - RJ/STF, que, por todo o argumentado, acertou na decisão.

O debate sobre o aborto não é recente e sempre trouxe consigo diversas polêmicas, sejam elas de cunho moral, ético, filosófico, religioso e, neste caso, especialmente, sob o aspecto jurídico. Não se trata de fazer demérito à vida que eventualmente esteja em processo de gestação e garantir respaldo à toda mulher que se encontre na situação de interrompê-la voluntariamente e vice-versa, mas de racionalizar, interpretando nossas leis, buscando sua essência, longe de convicções pessoais, morais, éticas, filosóficas e religiosas, uma problemática que, mesmo sendo criminalizada pela legislação, não obsta sua prática.

\section{REFERÊNCIAS}

ALEXY, Robert. Teoria dos Direitos Fundamentais. $5^{\mathrm{a}}$ ed. Tradução de Virgílio Afonso da Silva. São Paulo: Malheiros, 2008.

AVANCI, Thiago Felipe S. A colisão de direitos fundamentais: há colisão de direitos fundamentais? - Revista Brasileira de Direito Constitucional (RBDC): Revista do Programa de Pós-Graduação "Lato Sensu" em Direito Constitucional, São Paulo, 2010, n 16, p. 193 215, $2^{\circ}$ sem. 2010. Disponível em: http://www.esdc.com.br/RBDC/RBDC-16/RBDC-16-007INDICE.htm. Acesso em: 15 ago. 2018.

BARCELLOS, Ana Paula de. Curso de direito constitucional - Livro Digital - Rio de Janeiro: Forense, 2018.

BRASIL. Constituição da República dos Estados Unidos do Brasil. Diário Oficial da União, Seção 1, Rio de Janeiro - RJ, 10 NOV. 1937. Disponível em: http://www2.camara.leg.br/legin/fed/consti/1930-1939/constituicao-35093-10-novembro1937-532849-publicacaooriginal-15246-pl.html. Acesso em: 15 ago. 2018. 
BRASIL. Constituição da República Federativa do Brasil. Diário Oficial da União, Seção 1, Brasília, DF, 5 dez. 1988. Disponível em:

http://www2.camara.leg.br/legin/fed/consti/1988/constituicao-1988-5-outubro-1988-322142norma-pl.html. Acesso em: 15 ago. 2018.

BRASIL. Decreto no 678 de 6 de novembro de 1992. Promulga a Convenção Americana sobre Direitos Humanos (Pacto de São José da Costa Rica). Diário Oficial da União, Seção 1, de 9 nov. 1992, Página 2391. Disponível em: http://www2.camara.leg.br/legin/fed/decret/1992/decreto-678-6-novembro-1992-449028norma-pe.html. Acesso em: 30 ago. 2018.

BRASIL. Decreto-lei no 2.848, de 7 de dezembro de 1940. Código Penal. Diário Oficial da União, Seção 1, de 31/12/1940, Página 2391. Disponível em: http://www2.camara.leg.br/legin/fed/declei/1940-1949/decreto-lei-2848-7-dezembro-1940412868-norma-pe.html. Acesso em: 15 ago. 2018.

BRASIL. Lei $\mathbf{n}^{\mathbf{0}} \mathbf{1 1 . 1 0 5}$ de 24 de março de 2005. Lei de Biossegurança; Lei de Engenharia Genética. Diário Oficial da União, Seção 1, de 28/03/2005, Página 1. Disponível em: http://www2.camara.leg.br/legin/fed/lei/2005/lei-11105-24-marco-2005-536209publicacaooriginal-26498-pl.html. Acesso em: 14 ago. 2018.

BRASIL. Superior Tribunal de Justiça. Habeas Corpus 32.159/RJ. Relatora: Laurita Vaz Quinta Turma. Diário de Justiça, Brasília, 22 mar. 2004a. Disponível em: https://ww2.stj.jus.br/processo/revista/documento/mediado/?componente=ITA\&sequencial=4 50912\&num_registro=200302198405\&data=20040322\&formato=PDF. Acesso em: 14 ago. 2018.

BRASIL. Superior Tribunal de Justiça. Habeas Corpus 56.572/SP. Relator: Arnaldo Esteves Lima - Quinta Turma. Diário de Justiça, Brasília, 25 abr. 2006. Disponível em: https://ww2.stj.jus.br/processo/revista/documento/mediado/?componente=ITA\&sequencial=6 22824\&num_registro=200600626714\&data=20060515\&formato=PDF. Acesso em: 14 ago. 2018.

BRASIL. Supremo Tribunal Federal. Ação Direta de Inconstitucionalidade 3.510/DF. Relator: Carlos Ayres Britto - Tribunal Pleno. Diário de Justiça Eletrônico, Brasília, 28 mai. 2010. Disponível em: http://redir.stf.jus.br/paginadorpub/paginador.jsp?docTP=AC\&docID=611723. Acesso em: 14 ago. 2018.

BRASIL. Supremo Tribunal Federal. Arguição de Descumprimento de Preceito Fundamental 054/DF. Relator: Marco Aurélio Mello - Tribunal Pleno. Diário de Justiça Eletrônico, Brasília, 30 abr. 2013. Disponível em: http://redir.stf.jus.br/paginadorpub/paginador.jsp?docTP=TP\&docID=3707334. Acesso em: 14 ago. 2018.

BRASIL. Supremo Tribunal Federal. Habeas Corpus 124.306/RJ. Relator: Luís Roberto Barroso - Primeira Turma. Diário de Justiça Eletrônico, Brasília, 30 abr. 2013. Disponível 
em: http://redir.stf.jus.br/paginadorpub/paginador.jsp?docTP=TP\&docID=12580345. Acesso em: 14 ago. 2018.

BRASIL. Supremo Tribunal Federal. Habeas Corpus 84025/RJ. Relator: Joaquim Barbosa Tribunal Pleno. Diário de Justiça, Brasília, 25 jun. 2004b. Disponível em:

http://redir.stf.jus.br/paginadorpub/paginador.jsp?docTP=AC\&docID=384874. Acesso em: 14 ago. 2018.

BRASIL. Supremo Tribunal Federal. Mandado de Segurança 23452/RJ. Relator: Celso de Mello - Tribunal Pleno. Diário de Justiça, Brasília, 12 MAI. 2000. Disponível em:

http://redir.stf.jus.br/paginadorpub/paginador.jsp?docTP=AC\&docID=85966. Acesso em: 20 ago. 2018.

MARTINS, Ives Gandra. O direito constitucional comparado e a inviolabilidade da vida humana. In: PENTEADO, Jaques de C.; Ricardo Henry M. Dip (Org.). A vida dos direitos humanos - bioética médica e jurídica. Porto Alegre: Sergio Antônio Fabris Editor, 1999, p. 127-144

MENDES, Gilmar Ferreira; COELHO, Inocêncio Mártires; BRANCO, Paulo Gustavo G. Hermenêutica constitucional e direitos fundamentais. Brasília: Brasília Jurídica, 2000;

SARLET, Ingo Wolfgang; MARINONI, Luiz Guilherme; MITIDIERO, Daniel. Curso de direito constitucional. - 6 ed. rev. - Livro Digital - São Paulo: Saraiva, 2017.

SARMENTO, Daniel. Legalização do aborto e constituição. In: CAVALCANTE, Alcilene, Dulce Xavier (Org.). Em defesa da vida: aborto e direitos humanos. São Paulo: Católicas Pelo Direito de Decidir, 2006, Parte III, p. 117-180.

STEINMETZ, Wilson Antônio. Colisão de direitos fundamentais e princípio da proporcionalidade. 2000. 250 f. Dissertação (Mestrado) - Programa de Pós-Graduação em Direito, Setor de Ciências Jurídicas, Universidade Federal do Paraná, Paraná, 2000. Disponível em:

https://acervodigital.ufpr.br/bitstream/handle/1884/56635/WILSON\%20ANTONIO\%20STEI NMETZ.pdf?sequence=1\&isAllowed=y. Acesso em: 20 set. 2018.

STRECK, Lenio Luiz. Jurisdição Constitucional. - 5 ed. rev. - Livro Digital - Rio de Janeiro: Forense, 2018.

STRECK, Lenio Luiz. O que é isto - decido conforme minha consciência? - 4. ed. rev. Livro Digital - Porto Alegre: Livraria do Advogado Editora, 2013. 